\title{
No tenemos Vicki pero tenemos su legado
}

\author{
Eliana Belmonte Schwarzbaum ${ }^{1}$
}

Conocí a Vicki en 1987. En ese tiempo yo estaba enfrascada trabajando en el Museo de Azapa, descifrando la nervadura de las hojas que se encontraban dentro de las chuspas y ella venía a trabajar al Museo por periodos más o menos prolongados, coincidiendo con sus tiempos de descanso en el hemisferio norte. Siempre parecía poco el tiempo que compartía con nosotros; su presencia era evocadora de nuevas y siempre interesantes perspectivas, como cuando recorrimos valles costeros y quebradas cordilleranas buscando relacionar plantas y pigmentos.

Ambas tenemos ancestros judíos, lo que contribuyó a acercar lazos de cariño. Sin embargo, fue el terremoto de julio de 2001 que contribuyó a sellar nuestra amistad profunda, ya que nos sorprendió jugando con su hijo Victor y un amiguito de su edad entre La Liserilla y playa Corazones. Fueron momentos eternos y reales los que vivimos refugiados en una cueva con doble entrada, donde en lugar de puertas, veíamos caer una lluvia interminable de piedras de todos tamaños. En dos oportunidades quisimos salir porque sentimos que aminoraba el movimiento, pero tuvimos que regresar a nuestro refugio. Finalmente corriendo y sorteando todo tipo de rocas, llegamos hasta el estacionamiento y todo estaba en orden.
Su generosidad se difundía en todo sentido y se manifestó de diferentes formas, tanto en la vida cotidiana compartiendo labores manuales, recetas y delicias culinarias, como situaciones propias del mundo de la investigación. Fue en este campo donde también se dieron momentos de gran alegría y satisfacción. Los resultados de la composición botánica de las chuspas de sitios como AZ-140, PLM-3, AZ-6, LLu-50 sup, CAM-15 que íbamos recabando, daban cuenta de una diversidad reflejada al menos en el patrón de venación de las hojas. Vicki, se interesó muchísimo en estos datos, ya que también ella había trabajado cada una de estas mismas momias desde su particular punto de vista de conservación; posteriormente entusiasmó a Larry Cartmell para que estudiara el pelo de las momias, buscando metabolitos secundarios de la degradación de la coca. El cruce de todos estos datos junto a la visión y proyección de Vicki dio por resultado un artículo muy interesante (Cassman et al. 2003).

Y sobrevino lo inesperado. No tenemos Vicki pero tenemos su legado, su rigurosa forma de ver y de proyectar, su forma de invitar a participar y su elegante estilo, simple, sencillo, profundo. Fue un honor haberte conocido Vicki, estarás viva siempre en mi corazón.

\section{Referencia Citada}

Cassman, V.,L. Cartmell y E. Belmonte 2003. Coca as symbol and labor enhancer in the Andes: a historical overview. En Stimulating Trade:
Drugs, Labor and European Expansion, editado por W. Jankowiak y D. Bradburd, pp. 149-158. University of Arizona Press, Tucson.

\footnotetext{
${ }^{1}$ Universidad de Tarapacá, Arica, Chile.
} 